\title{
An inhibitor-driven study for enhancing the selectivity of indirubin derivatives towards leishmanial Glycogen Synthase Kinase-3 over leishmanial cdc2-related protein kinase 3
}

\author{
Antonia Efstathiou', Nicolas Gaboriaud-Kolar ${ }^{2,3}$, Despina Smirlis', Vassilios Myrianthopoulos², \\ Konstantina Vougogiannopoulou ${ }^{2,3}$, Alexandros Alexandratos ${ }^{1}$, Marina Kritsanida ${ }^{3}$, Emmanuel Mikros ${ }^{2}$, \\ Ketty Soteriadou ${ }^{1}$ and Alexios-Leandros Skaltsounis ${ }^{2,3^{*}}$
}

\begin{abstract}
Background: In search of new antiparasitic agents for overcoming the limitations of current leishmaniasis chemotherapy, we have previously shown that 6-bromoindirubin-3'-oxime (6BIO) and several other 6-substituted analogues of indirubin, a naturally occurring bis-indole present in mollusks and plants, displayed reverse selectivity from the respective mammalian kinases, targeting more potently the leishmanial Cyclin-Dependent Kinase-1 (CDK1) homologue [cdc2-related protein kinase 3 (LCRK3)] over leishmanial Glycogen Synthase Kinase-3 (LGSK-3). This reversal of selectivity in Leishmania parasites compared to mammalian cells makes the design of specific indirubin-based LGSK-3 inhibitors difficult. In this context, the identification of compounds bearing specific substitutions that shift indirubin inhibition towards LGSK-3, previously found to be a potential drug target, over LCRK3 is imperative for antileishmanial targeted drug discovery.

Methods: A new in-house indirubin library, composed of 35 compounds, initially designed to target mammalian kinases (CDKs, GSK-3), was tested against Leishmania donovani promastigotes and intracellular amastigotes using the Alamar blue assay. Indirubins with antileishmanial activity were tested against LGSK-3 and LCRK3 kinases, purified from homologous expression systems. Flow cytometry (FACS) was used to measure the DNA content for cell-cycle analysis and the mode of cell death. Comparative structural analysis of the involved kinases was then performed using the Szmap algorithm.

Results: We have identified 7 new indirubin analogues that are selective inhibitors of LGSK-3 over LCRK3. These new inhibitors were also found to display potent antileishmanial activity with $\mathrm{Gl}_{50}$ values of $<1.5 \mu \mathrm{M}$. Surprisingly, all the compounds that displayed enhanced selectivity towards LGSK-3, were 6BIO analogues bearing an additional 3'-bulky amino substitution, namely a piperazine or pyrrolidine ring. A comparative structural analysis of the two aforementioned leishmanial kinases was subsequently undertaken to explain and rationalize the selectivity trend determined by the in vitro binding assays. Interestingly, the latter analysis showed that selectivity could be correlated with differences in kinase solvation thermo dynamics induced by minor sequence variations of the otherwise highly similar ATP binding pockets.

(Continued on next page)
\end{abstract}

\footnotetext{
* Correspondence: skaltsounis@pharm.uoa.gr

${ }^{2}$ Laboratories of Pharmacognosy and Pharmaceutical Chemistry, Department of Pharmacy, University of Athens, Panepistimiopolis-Zografou, 15771 Athens, Greece

${ }^{3}$ Department of Pharmacognosy and Natural Product Chemistry, Faculty of Pharmacy, National and Kapodistrian University of Athens, Athens, Greece Full list of author information is available at the end of the article
} 
(Continued from previous page)

Conclusions: In conclusion, 3'-bulky amino substituted 6-BIO derivatives, which demonstrate enhanced specificity towards LGSK-3, represent a new scaffold for targeted drug development to treat leishmaniasis.

Keywords: Leishmania, Indirubins, LGSK-3, Szmap, Binding site solvation

\section{Background}

Leishmaniasis is a vector-borne neglected tropical disease caused by parasitic protozoa of the genus Leishmania [1]. Mammals, including humans, are infected by Leishmania promastigote parasites via the bite of female phlebotomine sand flies [2,3]. After Leishmania promastigotes pass into the mammalian blood, they are phagocytosed by macrophages and once located within the macrophages' phagolysosomes, promastigotes transform into the non-motile amastigote form and multiply [4]. More than 350 million people are at risk of Leishmania infection and about 1.5-2 million new cases and 500,000 deaths are considered to occur every year in the endemic areas [1]. The increasing resistance of Leishmania parasites and the toxicity of the current therapy as well as the non-existence of a human vaccine, generate an urgent need to discover effective, newtargeted drugs for treating leishmaniasis [5,6]. Research on natural products has been proved to be promising for discovering new lead structures in a variety of diseases including leishmaniasis [6]. Amongst natural product scaffolds, alkaloids display considerable structure diversity that can be exploited for the discovery of novel antileishmanials [6]. Moreover, marine indole-based alkaloid scaffolds [7] like variolin [8], roscovitine [9], leucettines [10] and halogenated indirubins [11], known to target kinases, represent a significantly large pool of compounds for the discovery of new targeted antileishmanial treatment $[12,13]$.

Specifically, indirubin is a naturally occurring bis-indole found in different species like indigo-bearing plants (Isatis spp., Polygonum spp.) or marine organisms (Murex shellfish family, Hexaplex trunculus) [11]. It has been identified as a potent inhibitor of protein kinases (CDKs) [14], whereas naturally halogenated indirubins such as 6-bromoindirubin (6BI) demonstrate selective inhibitory activity towards the mammalian Glycogen-Synthase Kinase-3 (GSK-3) [15]. The semi-synthetic analogue of 6BI, 6-bromoindirubin3 '-oxime (6BIO) was developed as a potent and selective GSK-3 $\beta$ inhibitor and is currently considered as one prototype inhibitor of that mammalian kinase [16].

The Cyclin-Dependent Kinase1 (CDK1) homologue of Leishmania [cdc2-related protein kinase 3 (LCRK3)] and the glycogen synthase kinase-3short (LGSK-3) have emerged amongst other kinases as putative molecular drug targets for the treatment of leishmaniasis [13,17-20]. LCRK3 was characterized by genetic analyses as an essential protein for parasite viability and a central regulator of cell-cycle progression [21]. Inhibition of LCRK3 in Leishmania para- sites resulted in a G2/M cell-cycle arrest, which was subsequently followed by an apoptosis-like death of the parasites $[13,21]$. Recently, the trypanosomatid GSK-3 was identified as a potential drug target for treatment of parasitic diseases $[13,19]$. In a previous study, we showed that LGSK-3 was essential for parasitic viability, and its inhibition caused cell-cycle defects and apoptosis-like death [13]. We have previously shown that 6-substituted indirubin analogues, including 6BIO, inhibit more potently LCRK3 than LGSK3 , a reverse selectivity compared to the corresponding mammalian homologues. The only exceptions to this reversal were the bisubstituted 5-methyl-6-bromoindirubin-3' -oxime (5-Me-6BIO) which was 7-fold more selective towards LGSK-3 over LCRK3 and 6-bromoindirubin-3'acetoxime (6-BIA) which inhibited both kinases equally well [13]. This reversal indicated that the mammalian GSK-3/CDK1 selectivity determinants differ from the corresponding parasitic ones. Herein, we describe the evaluation of indirubin analogues, initially designed to target mammalian kinases, against Leishmania parasites. One main objective of this study was to improve indirubin selectivity towards LGSK-3 over LCRK3. This knowledge is important for antileishmanial drug discovery since previous studies showed that LCRK3 inhibition did not translate very well into antiparasitic activity [18,22]. In addition, this knowledge is anticipated to be crucial for Structure Activity Relationship studies (SARs) and modification of the lead compound to more potent and specific inhibitor. Overall, this approach led to the identification of indirubin based antileishmanial agents favoring inhibition of LGSK-3 over LCRK3. Interestingly, the compounds with LGSK-3 specificity were $6 \mathrm{BIO}$ derivatives possessing bulky amino substitution namely a piperazine or pyrrolidine ring at position $3^{\prime}$, suggesting that these substitutions increase the affinity of the compound towards LGSK-3 but not towards LCRK3. A comparative structural analysis of the two aforementioned parasitic kinases was undertaken as a means to explain and rationalize the selectivity trend determined by in vitro assays, showing that the enhanced selectivity of 6-bromo-3'-substituted indirubins for LGSK-3 can be attributed to differences in the solvation pattern of the otherwise similar ATP binding pocket.

\section{Methods}

\section{Chemical synthesis}

The studied compounds have been synthesized according to the methodology developed previously $[11,16,23,24]$. 


\section{Evaluation of the antileishmanial activity of indirubins against $L$. donovani promastigotes and intracellular amastigotes in vitro}

All compounds were dissolved in DMSO at $10 \mathrm{mM}$ and serial dilutions in DMSO were made ( $1 \mathrm{mM}$ and $100 \mu \mathrm{M})$. The analogues were further diluted in the culture medium to give the desired final concentrations.

The antileishmanial activity was determined using the Alamar blue assay [25]. L. donovani promastigotes (MHOM/ET/0000/HUSSEN) which were frequently passed in BALB/c mice [26] were used in all experiments. Specifically, $2.5 \times 10^{6}$ cells $/ \mathrm{ml}$ of $L$. donovani promastigotes in the stationary phase were seeded into 96-well flat bottom plates in total volume of $200 \mu \mathrm{l} \mathrm{M199}$ without phenol red per well. In triplicates, indirubins were added in increasing concentrations and equivalent volumes of the solvent DMSO $(<0.1 \% \mathrm{v} / \mathrm{v})$ were used as control. After incubation of the parasites for $72 \mathrm{hrs}$ at $26^{\circ} \mathrm{C}$, Alamar blue (20 $\mathrm{\mu l} /$ well) was added for a further $24 \mathrm{hrs}$ and colorimetric changes were read at $550 \mathrm{~nm}$ with reference wavelength $620 \mathrm{~nm}$. Calculation of the compound concentration that induces $50 \%$ reduction of the growth rate of the promastigotes $\left(\mathrm{GI}_{50}\right.$ values for $50 \%$ growth inhibition) was performed using the parasites treated with DMSO as control growth rate sample. $\mathrm{GI}_{50}$ values were determined from dose-response curves via linear interpolation.

For the in vitro infection evaluation of indirubins' antileishmanial activity, $2 \times 10^{5} \mathrm{~J} 774.1$ cell line macrophages per $\mathrm{ml}$ in $200 \mu \mathrm{l}$ RPMI supplemented with 10\% (v/v) HIFBS (heat-inactivated fetal bovine serum), $10 \mathrm{mM}$ HEPES and penicillin-streptomycin (final concentration $100 \mathrm{U} \mathrm{ml}^{-1}$ ), were seeded into 96-well flat bottom plates. The macrophages were left to adhere overnight at $37^{\circ} \mathrm{C}$ in an atmosphere of $5 \% \mathrm{CO}_{2}$. Afterwards, the macrophage infection was performed at a ratio of 10 parasites/macrophage for $24 \mathrm{hrs}$ at $37^{\circ} \mathrm{C}$ in $5 \% \mathrm{CO}_{2}$, followed by the incubation of the infected macrophages with the indirubins for $72 \mathrm{hrs}$. DMSO-treated macrophages, which were infected with parasites, were used as controls. After this $72 \mathrm{hrs}$ period and the removal of the medium, the macrophages were lysed with $100 \mu \mathrm{l} 0.01 \%$ (v/v) SDS in PBS for $30 \mathrm{~min}$ at $37^{\circ} \mathrm{C}$. Then, $100 \mu \mathrm{l}$ Schneider's medium was added to each well and amastigote growth was assessed by the addition of Alamar blue $(20 \mu \mathrm{l} /$ well $)$ and the plates were incubated for $48 \mathrm{hrs}$ at $37^{\circ} \mathrm{C}$ [27]. Calculation of the $\mathrm{GI}_{50}$ values was performed as previously described [13].

In order to confirm the in vitro infection evaluation results of indirubins' antileishmanial activity, we also performed the assay with $2 \times 10^{5}$ peritoneal macrophages, collected from BALB/c mice (4-6 weeks old), $72 \mathrm{hrs}$ after the intraperitoneally administration of $1 \mathrm{ml}$ sterile thioglycollate medium (4\% w/v, Becton Dickinson, Sparks, MD, USA). The mice, which were used with prior approval by the Animal Bioethics Committee of the Hellenic Pasteur
Institute (HPI; Athens, Greece) according to the Directive 2010/63/EE of the council of Europe, for the protection of vertebrates/animals, were euthanized for the recovery of peritoneal macrophages. The peritoneal macrophages were centrifuged $\left(1,200 \mathrm{rpm}, 4^{\circ} \mathrm{C}, 10 \mathrm{~min}\right)$ and washed 3 times with RPMI-1640 medium. After the collection of the peritoneal macrophages the steps followed were the same as the ones described above for the in vitro infection assay with J774.1 cell line macrophages.

For the compounds 11-17, the intracellular amastigote assay was performed at first with both murine macrophagic cell-line J774.1 and peritoneal macrophages extracted from BALB/c mice. The results from both assays were significantly similar (data not shown) and therefore the following experiments were performed with J774.1 murine macrophages.

\section{Cell-cycle and cell-death analysis of indirubin-treated promastigotes by flow cytometry}

$L$. donovani promastigotes in the stationary phase $\left(2 \times 10^{7}\right.$ cells $\left./ \mathrm{ml}\right)$ were seeded at $10^{6}$ cells $/ \mathrm{ml}$ in M199 medium and incubated for $48 \mathrm{hrs}$, at $26^{\circ} \mathrm{C}$ with the $\mathrm{GI}_{50}$ concentration of each analogue or with DMSO, as control. For the analysis of the cell cycle, the procedure described in Georgopoulou et al. [28], was followed to prepare the samples for fluorescence-activated cell sorting. In order to determine the amount of cells, which display membrane fluidity perturbations, FACS analysis was performed using AnnexinV-FITC and propidium iodide (PI) staining (Apoptosis Detection kit, R \& D Systems). All samples were analyzed using a Becton Dickinson FACS Calibur flow cytometer and data were analyzed using the Cell Quest software. All experiments were performed in triplicates.

\section{Kinase assays}

Recombinant LGSK-3 and LCRK3 were produced and purified from $L$. donovani over-expressing transfectants and transgenic $L$. mexicana promastigotes respectively, as previously described [13]. LCRK3 expressing L. mexicana parasites were a kind gift from Dr. K. Grant. The Kinase Luminescent Assay Kit (Promega) was used to perform the kinase assays, following the manufacturer's instructions as previously described [13]. For determining the kinase activity of LGSK-3, GS-1 peptide was used as a substrate (YRRAAVPPSPSLSRHSSPHQSpEDEEE) [29] while LCRK3 kinase assays were performed using histone $\mathrm{H} 1$ as a substrate [18], with increasing concentrations of each compound. $\mathrm{IC}_{50}$ values $(\mu \mathrm{M})$ were determined from doseresponse curves. All experiments were performed in triplicates.

\section{Computational analysis}

Homology models were built for LGSK-3 and LCRK3 of three Leishmania species (L. major, L. donovani, $L$. 
infantum-Uniprot codes Q4QE15, A6N857, A4HXQ3, O96526, Q7K8Z1, A4ICT0) using Prime 3.1 and the corresponding cocrystal structures of human GSK-3 and CDK5 with indirubin (pdb codes $1 \mathrm{UV} 5,1 \mathrm{UNH}$ ) as templates [30]. Computational analysis of protein solvation was performed using Szmap algorithm. Szmap implements a semi-continuous solvation model for mapping the surface of the protein and identifies hydration sites of positive (unstable) and negative (stable) free energy. Characterization of water molecules according to their free energy permits rational design of high affinity ligands, which either displace unstable waters or replace stable waters by polar groups of similar capability for accommodating electrostatic interactions with the protein.

\section{Results and discussion}

In order to understand which specific substitutions on the indirubin analogues contribute to LGSK-3 selectivity, we evaluated a larger collection of indirubin analogues designed to target several mammalian kinases including CDKs and GSK-3, with pleiotropic substitutions in the indirubin backbone (Table 1). The indirubin scaffold was substituted with various functional groups, interventions initially designed for effective inhibition of mammalian GSK-3 [23]. Those 6BIO analogues bear bulky and hydrophilic amino chains in position 3' aiming at the enhancement of the otherwise low indirubin watersolubility. To this end, we screened this set against $L$. donovani promastigotes (the insect form) and intracellular amastigotes (the form found in mammals) at $3 \mu \mathrm{M}$ (Table 1). Their toxicity against the murine macrophagic cell-line J774.1 was assessed at $10 \mu \mathrm{M}$ (Table 1). This initial screening showed that 9 out of 35 analogues, were able to induce $100 \%$ growth inhibition when tested against $L$. donovani promastigotes form at $3 \mu \mathrm{M}$. Both forms of the studied 6BIO analogues (free base and hydrochloride salt) were tested yet only one pair of compounds presented a small difference in activity (salt $\mathbf{1 1}$ was found active against $L$. donovani promastigotes compared to its corresponding base $\mathbf{1 0}$ which was inactive at $3 \mu \mathrm{M}$ ). This minor discrepancy can be attributed to differences in cell permeability between the two forms of the compound. Indeed, $\mathbf{1 0}$ is the only analogue possessing a non-substituted piperazine group and thus demonstrates a higher $\mathrm{pKa}(\approx 1$ unit) value. This physicochemical parameter could have an effect on the overall solubility of $\mathbf{1 0}$ at the $\mathrm{pH}$ of culture media, resulting to the observed difference in activity. Such discrepancies between free base and corresponding salt forms have been described in previous studies reporting activity of antitrypanosomal agents against parasites [31]. Compounds 4 and 5 that were active against $L$. donovani promastigotes, with a $\mathrm{GI}_{50}$ of $1.15 \pm 0.06$ and $0.9 \pm 0.11$ respectively, were found to be toxic to the murine macrophagic cell-line J774.1
$\left(\mathrm{GI}_{50}: 1.5 \pm 0.07\right.$ and $1.5 \pm 0.08$ respectively). Thus, these compounds were not further studied for their activity against intracellular amastigotes. Subsequently, $\mathrm{GI}_{50}$ values $(\mu \mathrm{M})$ of compounds 11-17 for both L. donovani promastigote and amastigote forms were determined.

Indirubin analogues possessing halogeno groups $\left(\mathrm{Br}, \mathrm{CF}_{3}\right)$ in position 7 had no significant effect on $L$. donovani promastigote $\left(\mathrm{GI}_{50}>3 \mu \mathrm{M}\right)$ and intracellular amastigote growth $\left(\mathrm{GI}_{50}>3 \mu \mathrm{M}\right)$ (Table 1$)$. On the contrary, the 3 ' amino chain substituted $6 \mathrm{BIO}$ analogues 11-17 displayed antileishmanial activity against promastigotes at the low micromolar or nanomolar range $\left(\mathrm{GI}_{50}\right.$ : 0.65-1.50 $\left.\mu \mathrm{M}\right)$. For these compounds, the intracellular amastigote assay was performed. Notably, the $\mathrm{GI}_{50}$ values obtained $\left(\mathrm{GI}_{50}\right.$ : $0.59-2.44 \mu \mathrm{M})$ were in the same range with the previously reported values of $6 \mathrm{BIO}$ and 5-Me-6-BIO [13]. The analogues 11-15 shown in Table 1 inhibited the $L$. donovani promastigotes and intracellular amastigotes equally well. Derivatives $\mathbf{1 6}$ and $\mathbf{1 7}$ inhibited the promastigotes with a $\mathrm{GI}_{50}$ of $0.76 \pm 0.03 \mu \mathrm{M}$ and $0.76 \pm 0.04 \mu \mathrm{M}$ respectively, but their inhibitory effects against intracellular amastigotes were slightly lower $\left(\mathrm{GI}_{50}: 1.54 \pm 0.11 \mu \mathrm{M}\right.$ and $1.22 \pm 0.06 \mu \mathrm{M}$ respectively). Interestingly, compounds 11 and 17 displayed a good selectivity index $(>8)$ over the murine macrophagic cell-line J774.1, which was used to assess indirubin cytotoxicity (Table 1).

Next, we selected the indirubin analogues with antileishmanial activity (11-17) to evaluate their inhibitory effect towards LGSK-3 and LCRK3 kinases. In addition, to confirm that the selection of the compounds was unbiased, we selected several indirubins with no antileishmanial activity (compounds $2,27,30,33$ ) to perform the kinase assay. The parasitic kinases (LGSK-3 and LCRK3) were purified from homologous expression systems as previously described $[13,18]$. The $\mathrm{Km}$ values of both kinases for ATP and their respective substrate were in accordance to those previously reported [13]. The $\mathrm{IC}_{50}$ values were calculated from the dose-response curves. $6 \mathrm{BIO}$ and 5-Me-6-BIO [13] were tested in parallel and were used as reference controls. Interestingly, results obtained using in vitro assays against LGSK-3 and LCRK3 kinases, showed that the $6 \mathrm{BIO}$ analogues substituted with a piperazine or pyrrolidine ring at position 3'shifted the 6BIO selectivity towards LGSK-3 (Table 2). On the other hand, the selected analogues with no antileishmanial activity (compounds 2, 27, 30,33), did not display any relevant activity towards $L$ GSK-3 or LCRK3 $\left(\mathrm{IC}_{50}>3.33 \mu \mathrm{M}\right.$ ) (data not shown).

Thus, herein (Table 2), we showed that the 7-fold selectivity displayed by $6 \mathrm{BIO}$ towards $L$ CRK3 over LGSK-3 was shifted to LGSK-3 over LCRK3 selectivity upon the incorporation of a nitrogen-containing saturated ring in position 3' of the indirubin core. This type of substitution could enhance the affinity of the scaffold towards 
Table 1 Inhibitory activity of the studied indirubin analogues against L. donovani promastigotes and intracellular amastigotes

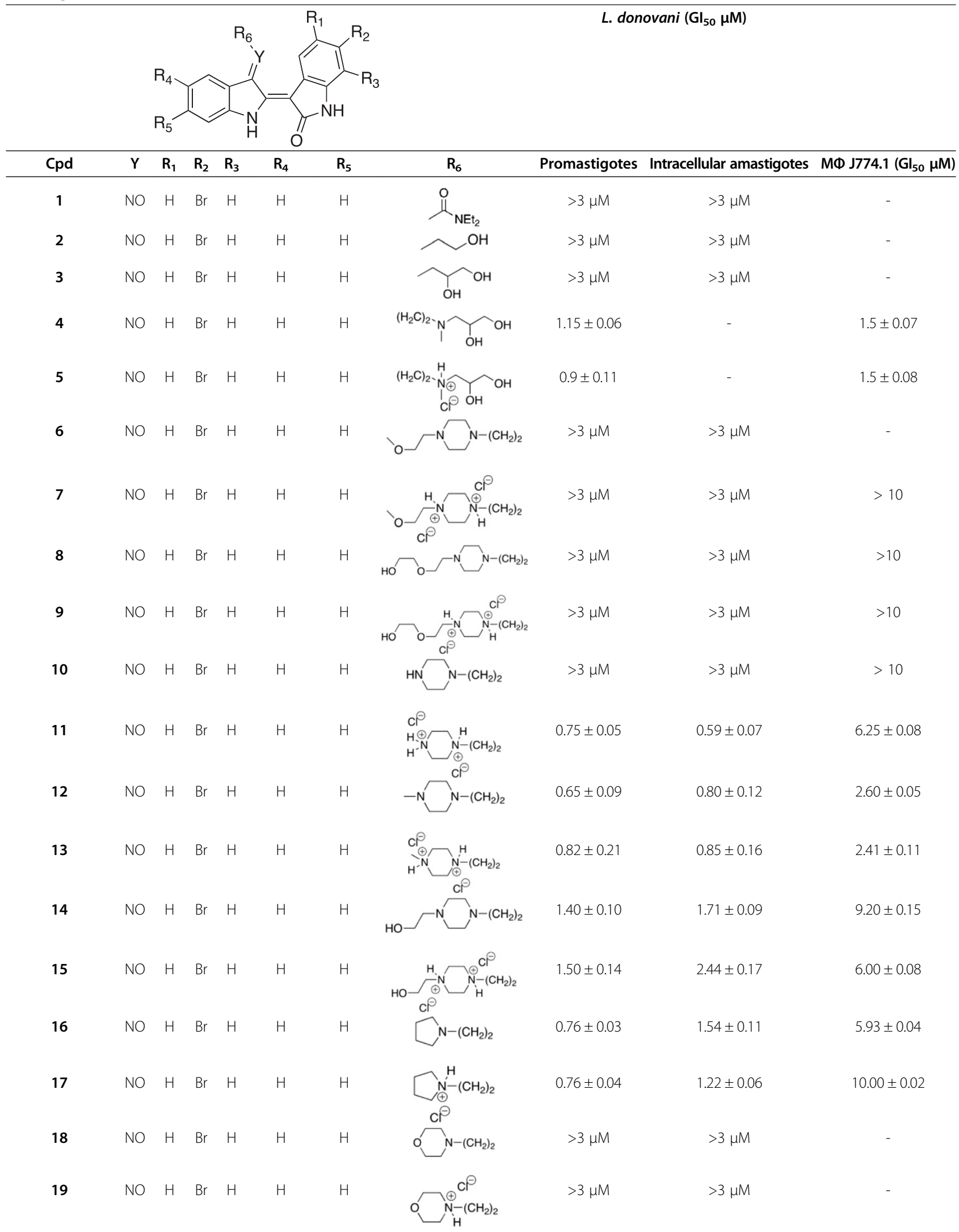


Table 1 Inhibitory activity of the studied indirubin analogues against $L$. donovani promastigotes and intracellular amastigotes (Continued)

\begin{tabular}{|c|c|c|c|c|c|c|c|c|c|c|}
\hline 20 & $\mathrm{O}$ & $\mathrm{H}$ & $\mathrm{H}$ & $\mathrm{Br}$ & $\mathrm{H}$ & $\mathrm{H}$ & - & $>3 \mu \mathrm{M}$ & $>3 \mu \mathrm{M}$ & - \\
\hline 21 & NO & $\mathrm{H}$ & $\mathrm{H}$ & $\mathrm{Br}$ & $\mathrm{H}$ & $\mathrm{H}$ & $\mathrm{H}$ & $>3 \mu \mathrm{M}$ & $>3 \mu \mathrm{M}$ & $>10$ \\
\hline 22 & $\mathrm{O}$ & $\mathrm{H}$ & $\mathrm{H}$ & $\mathrm{Br}$ & $\mathrm{COOH}$ & $\mathrm{H}$ & - & $>3 \mu \mathrm{M}$ & $>3 \mu \mathrm{M}$ & - \\
\hline 23 & NO & $\mathrm{H}$ & $\mathrm{H}$ & $\mathrm{Br}$ & $\mathrm{COOH}$ & $\mathrm{H}$ & $H$ & $>3 \mu \mathrm{M}$ & $>3 \mu \mathrm{M}$ & - \\
\hline 24 & 0 & $\mathrm{H}$ & $\mathrm{H}$ & $\mathrm{Br}$ & $\mathrm{H}$ & $\mathrm{COOH}$ & - & $>3 \mu \mathrm{M}$ & $>3 \mu \mathrm{M}$ & - \\
\hline 25 & NO & $\mathrm{H}$ & $\mathrm{H}$ & $\mathrm{Br}$ & $\mathrm{H}$ & coOMe & $\mathrm{H}$ & $>3 \mu \mathrm{M}$ & $>3 \mu \mathrm{M}$ & - \\
\hline 26 & NO & $\mathrm{H}$ & $\mathrm{H}$ & $\mathrm{Br}$ & $\mathrm{H}$ & $\mathrm{COOH}$ & $\mathrm{H}$ & $>3 \mu \mathrm{M}$ & $>3 \mu \mathrm{M}$ & - \\
\hline 27 & NO & $\mathrm{H}$ & $\mathrm{H}$ & $\mathrm{CF}_{3}$ & $\mathrm{H}$ & $\mathrm{H}$ & $\mathrm{H}$ & $>3 \mu \mathrm{M}$ & $>3 \mu \mathrm{M}$ & - \\
\hline 28 & NO & $\mathrm{H}$ & $\mathrm{H}$ & $\mathrm{CF}_{3}$ & COOMe & $\mathrm{H}$ & $\mathrm{H}$ & $>3 \mu \mathrm{M}$ & $>3 \mu \mathrm{M}$ & - \\
\hline 29 & O & $\mathrm{H}$ & $\mathrm{H}$ & $\mathrm{CF}_{3}$ & $\mathrm{COOH}$ & $\mathrm{H}$ & - & $>3 \mu \mathrm{M}$ & $>3 \mu \mathrm{M}$ & - \\
\hline 30 & NO & $\mathrm{H}$ & $\mathrm{H}$ & $\mathrm{CF}_{3}$ & $\mathrm{COOH}$ & $\mathrm{H}$ & $\mathrm{H}$ & $>3 \mu \mathrm{M}$ & $>3 \mu \mathrm{M}$ & - \\
\hline 31 & O & $\mathrm{H}$ & $\mathrm{H}$ & $\mathrm{CF}_{3}$ & $\mathrm{H}$ & $\mathrm{COOH}$ & - & $>3 \mu \mathrm{M}$ & $>3 \mu \mathrm{M}$ & - \\
\hline 32 & NO & $\mathrm{H}$ & $\mathrm{H}$ & $\mathrm{CF}_{3}$ & $\mathrm{H}$ & COOMe & $\mathrm{H}$ & $>3 \mu \mathrm{M}$ & $>3 \mu \mathrm{M}$ & $>10$ \\
\hline 33 & NO & $\mathrm{H}$ & $\mathrm{H}$ & $\mathrm{CF}_{3}$ & $\mathrm{H}$ & $\mathrm{COOH}$ & $\mathrm{H}$ & $>3 \mu \mathrm{M}$ & $>3 \mu \mathrm{M}$ & - \\
\hline 34 & $\mathrm{O}$ & $\mathrm{H}$ & $\mathrm{H}$ & $\mathrm{CF}_{3}$ & & $\mathrm{H}$ & - & $>3 \mu \mathrm{M}$ & $>3 \mu \mathrm{M}$ & - \\
\hline 35 & NO & $\mathrm{H}$ & $\mathrm{H}$ & $\mathrm{CF}_{3}$ & $\mathrm{~N}^{-\mathrm{H}}$ & $\mathrm{H}$ & $\mathrm{H}$ & $>3 \mu \mathrm{M}$ & $>3 \mu \mathrm{M}$ & - \\
\hline $6 \mathrm{BIO}$ & NO & $\mathrm{H}$ & $\mathrm{Br}$ & $\mathrm{H}$ & H & $\mathrm{H}$ & $\mathrm{H}$ & $0.85 \pm 0.05$ & $0.70 \pm 0.10$ & $>25$ \\
\hline 5-Me-6-BIO & NO & $\mathrm{CH}_{3}$ & $\mathrm{Br}$ & $\mathrm{H}$ & $\mathrm{H}$ & $\mathrm{H}$ & $\mathrm{H}$ & $1.2 \pm 0.2$ & $1.0 \pm 0.1$ & $>25$ \\
\hline Amphotericin B & - & - & - & - & - & - & - & $0.10 \pm 0.01$ & $0.20 \pm 0.02$ & - \\
\hline
\end{tabular}

$\mathrm{Gl}_{50}(\mu \mathrm{M})$ of compounds tested in vitro for their antileishmanial activity against $L$. donovani promastigotes and intracellular amastigotes, and their cytotoxicity against murine macrophages $\mathrm{J774} 1 . \mathrm{GI}_{50}(\mu \mathrm{M})$ of the controls Amphotericin $\mathrm{B}, 6-\mathrm{BIO}$ and 5-Me-6-BIO is also shown. Inhibitory activity was evaluated using the Alamar blue assay, as previously described. $\mathrm{Gl}_{50}$ values were determined from dose-response curves via linear interpolation.

the hydrophilic sites of the binding pocket of LGSK-3, making these analogues more selective. As shown in Table 2, compound $\mathbf{1 1}$ which possesses only an additional piperazine ring substitution, displays a $>33$-fold degree of selectivity for $L$ GSK-3 over $L$ CRK3. These results indicate that the substitution of the oxime in position $3^{\prime}$ is an important feature for LGSK-3 inhibition. This finding is consistent with our previous observation that 6BIA inhibited LGSK-3 more potently [13].

In order to evaluate if the in vitro results of the shifted LGSK-3 over LCRK3 selectivity displayed by the analogues 11 and 17, are also mirrored in cellulo, we have further examined their effect on the cell-cycle progression and the induction of parasitic cell-death. To this end, we have analyzed the cell-cycle progression in the L. donovani promastigotes after 24 and $48 \mathrm{hrs}$ treatment with the compounds 11 and $\mathbf{1 7}$. Indirubins were used at the $\mathrm{GI}_{50}$ concentration. 5-Me-6BIO and $6 \mathrm{BIO}$, known to induce cell-cycle arrest in the G1 phase by inhibiting LGSK-3 and G2/M arrest by inhibiting LCRK3 respectively [13], were tested in parallel (Figure 1). Herein, $L$. donovani promastigotes treated with compounds 11 and 17 resulted in a rapid increase in the percentage of
subG0/G1 cells (Figure 1). Cells treated with vehicle only $[0.02 \%(\mathrm{v} / \mathrm{v})$ DMSO], which were used as negative control, showed a normal distribution of the cell-cycle at all time-points studied (Figure 1). These results were in accordance with the distribution of the selective LGSK3 inhibitor 5-Me-6-BIO, which served as a model

Table 2 Inhibition of L. donovani LGSK-3 and L. mexicana LCRK3 by compounds 11-17

\begin{tabular}{ccc}
\hline & \multicolumn{2}{c}{$I_{50}(\mu \mathrm{M})$} \\
\cline { 2 - 3 } Compounds & LGSK-3 & LCRK3 \\
\hline 6-BIO & $0.15 \pm 0.06$ & $0.02 \pm 0.01$ \\
5-Me-6-BIO & $0.09 \pm 0.02$ & $0.65 \pm 0.09$ \\
$\mathbf{1 1}$ & $0.10 \pm 0.07$ & $>3.33$ \\
$\mathbf{1 2}$ & $0.20 \pm 0.08$ & $0.99 \pm 0.19$ \\
$\mathbf{1 3}$ & $1.65 \pm 0.17$ & $>3.33$ \\
$\mathbf{1 4}$ & $1.95 \pm 0.11$ & $>3.33$ \\
$\mathbf{1 5}$ & $0.17 \pm 0.25$ & $0.14 \pm 0.06$ \\
$\mathbf{1 6}$ & $0.36 \pm 0.18$ & $>3.33$ \\
$\mathbf{1 7}$ & $0.88 \pm 0.26$ & $>3.33$ \\
\hline
\end{tabular}

Inhibitory kinase activity of the controls 6BIO and 5-Me-6-BIO is also shown. $\mathrm{IC}_{50}$ values are expressed in $\mu \mathrm{M}$. 
A. Control

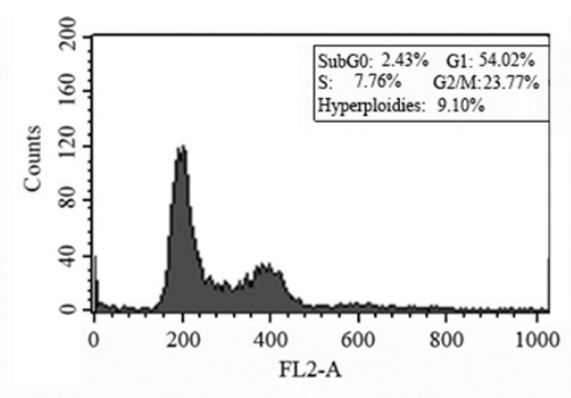

$24 \mathrm{~h}$
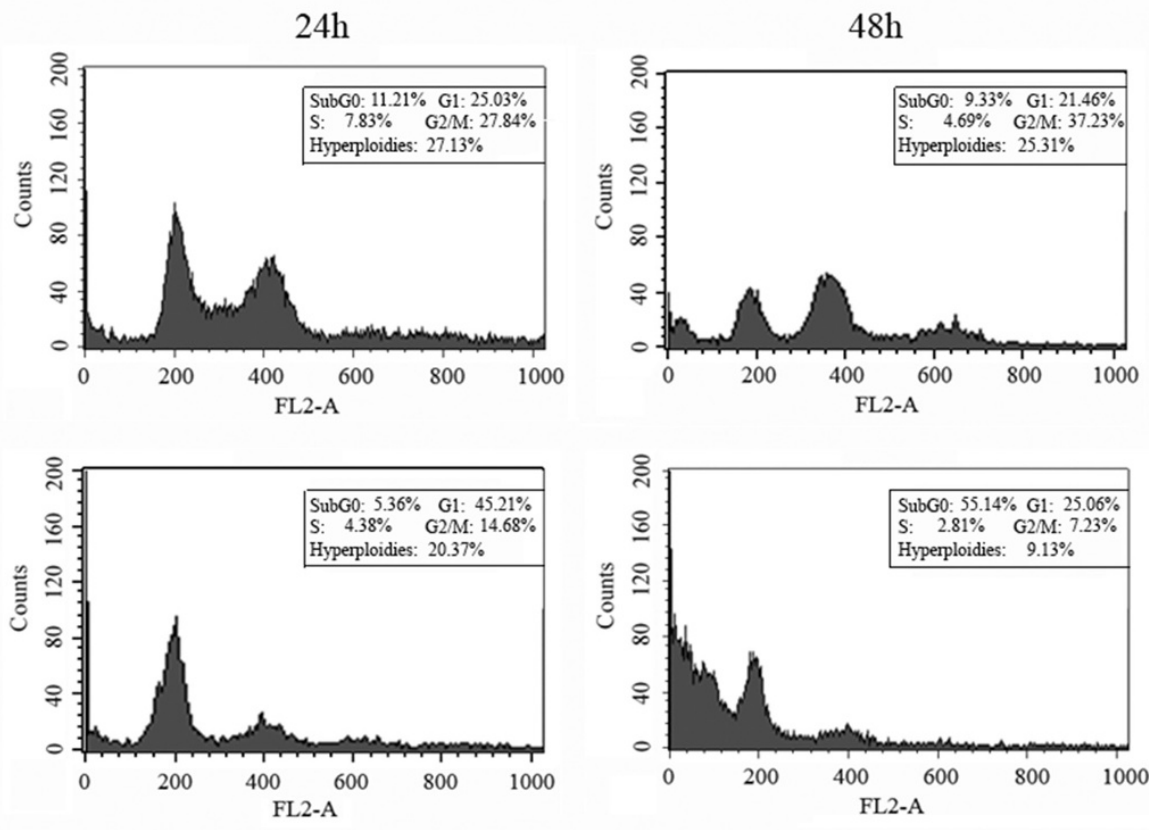

C. 5-Me-6-BIO
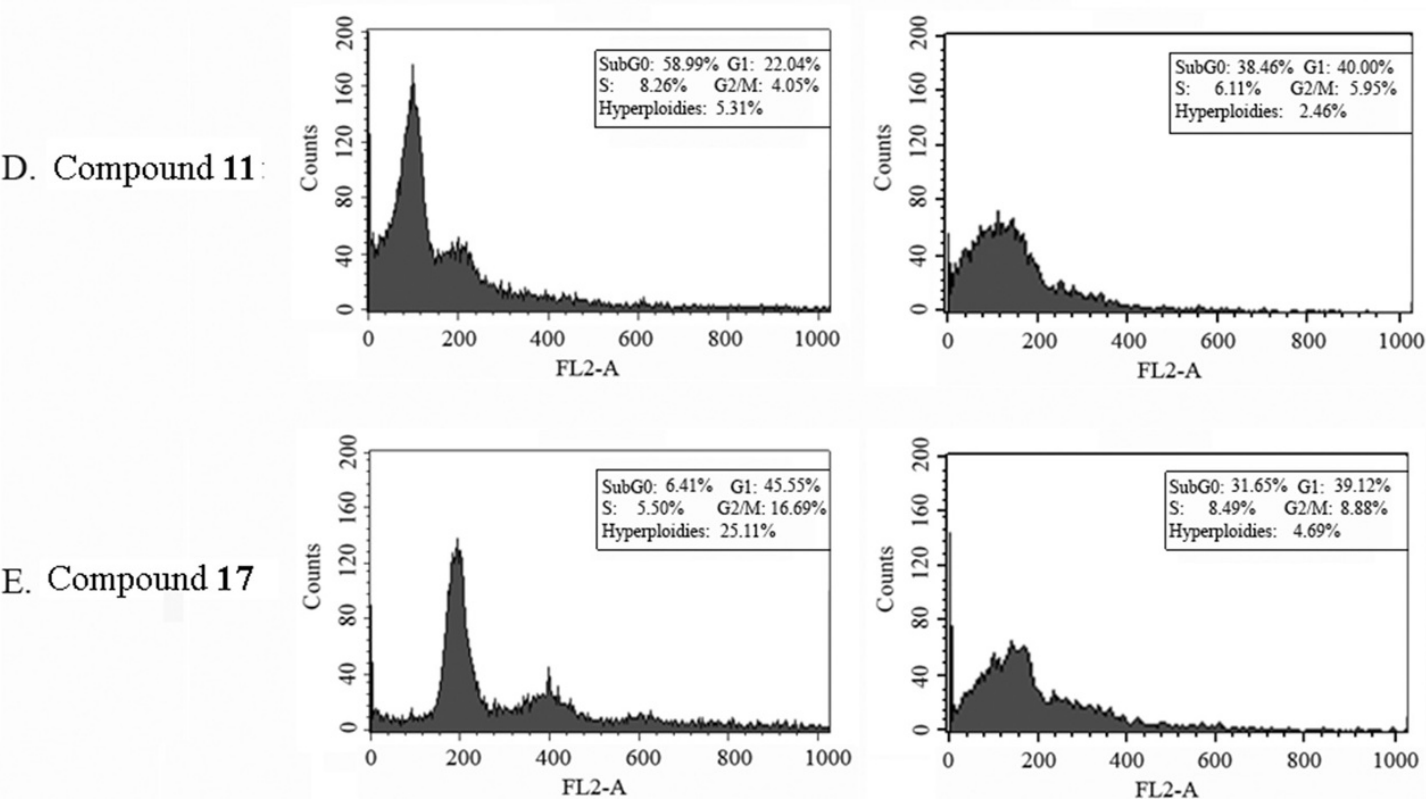

Figure 1 Cell-cycle analysis of indirubin-treated cells by flow cytometry. DNA content of parasites treated with vehicle only (A, control, DMSO $<0.1 \%$ ) and parasites treated with $\mathrm{Gl}_{50}$ concentration of compounds 11 (D), 17 (E). Compounds 6BIO (B) and 5-Me-6-BIO (C) were used as controls. The DNA content was measured by staining cells with propidium iodide (PI) and the cell-cycle status was analyzed by flow cytometry. 

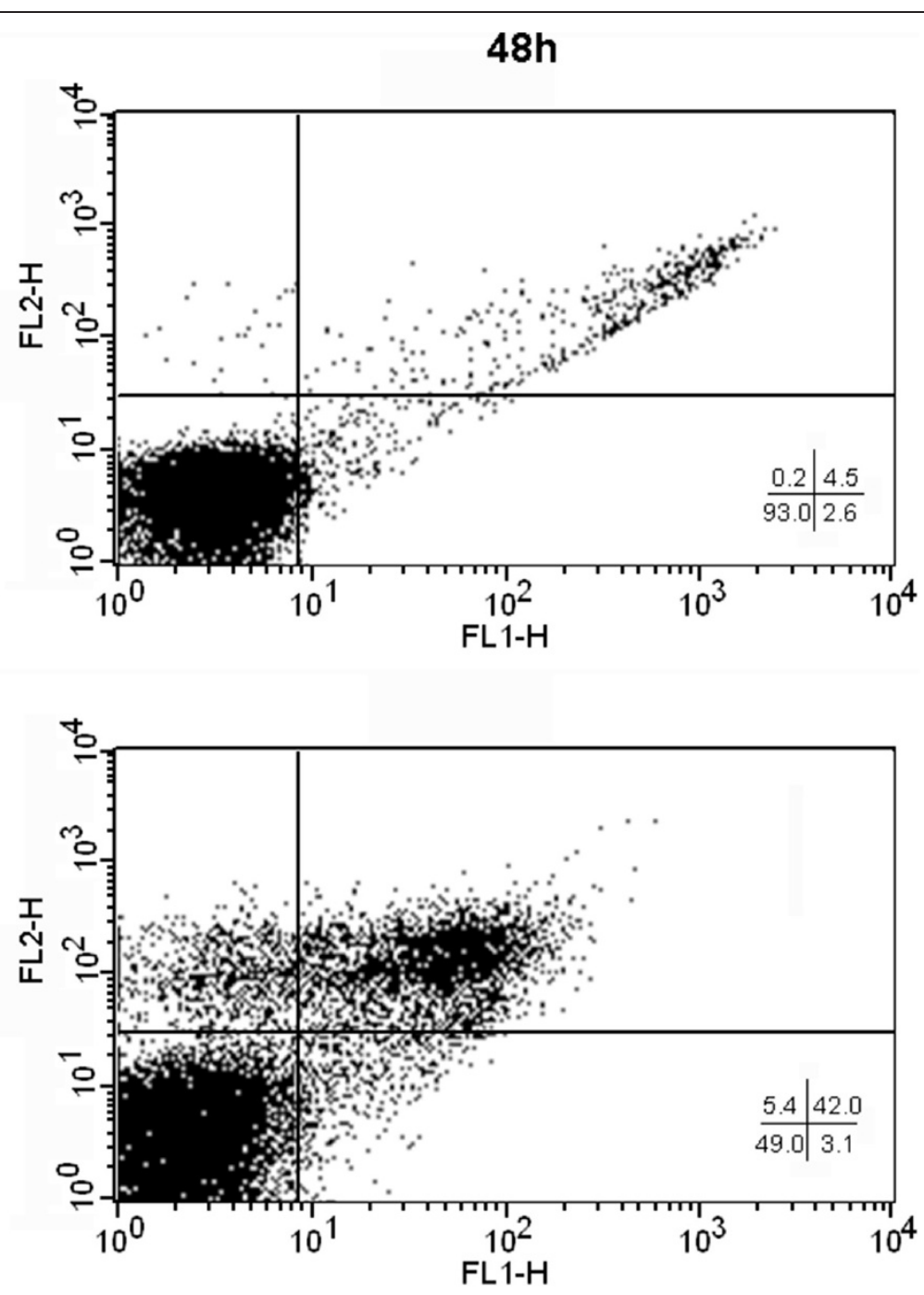

C. Compound 17

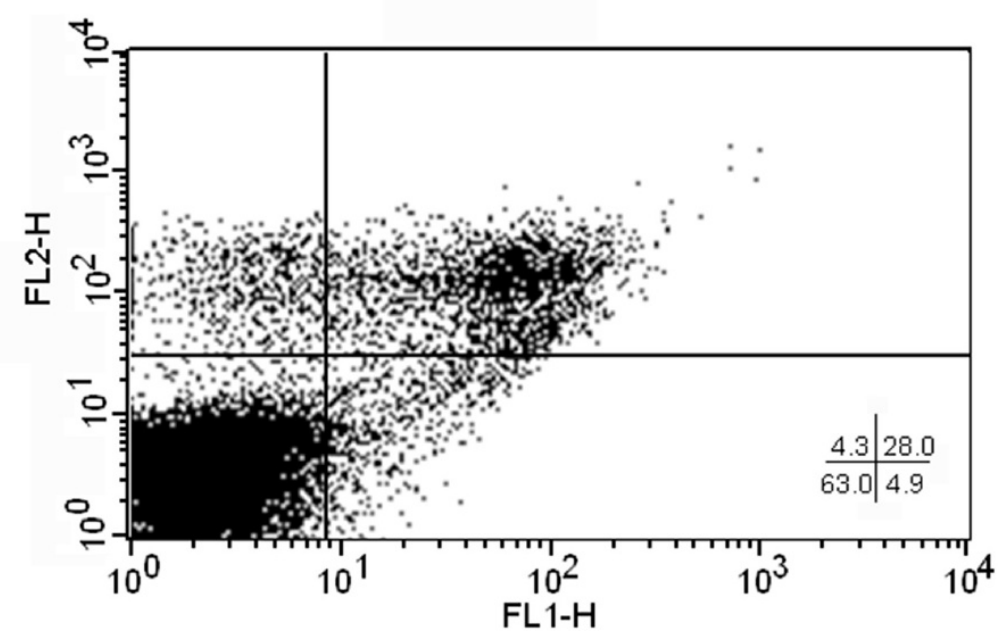

Figure $\mathbf{2}$ (See legend on next page.) 
(See figure on previous page.)

Figure 2 Effect of indirubin analogues 11 and 17 on the cell-death of L. donovani promastigotes. Effect of compounds 11 (B) and 17 (C) on the cell-death of $L$. donovani promastigotes, incubated with the $\mathrm{Gl}_{50}$ of each compound for 48 hrs. Cells were stained with AnnexinV-FITC (horizontal axis, FL1-H) and propidium iodide PI (vertical axis, FL2-H) to assess membrane fluidity perturbations (AnnexinV staining) and membrane impermeability. The samples were then analyzed by flow cytometry. DMSO was used as negative control (A).
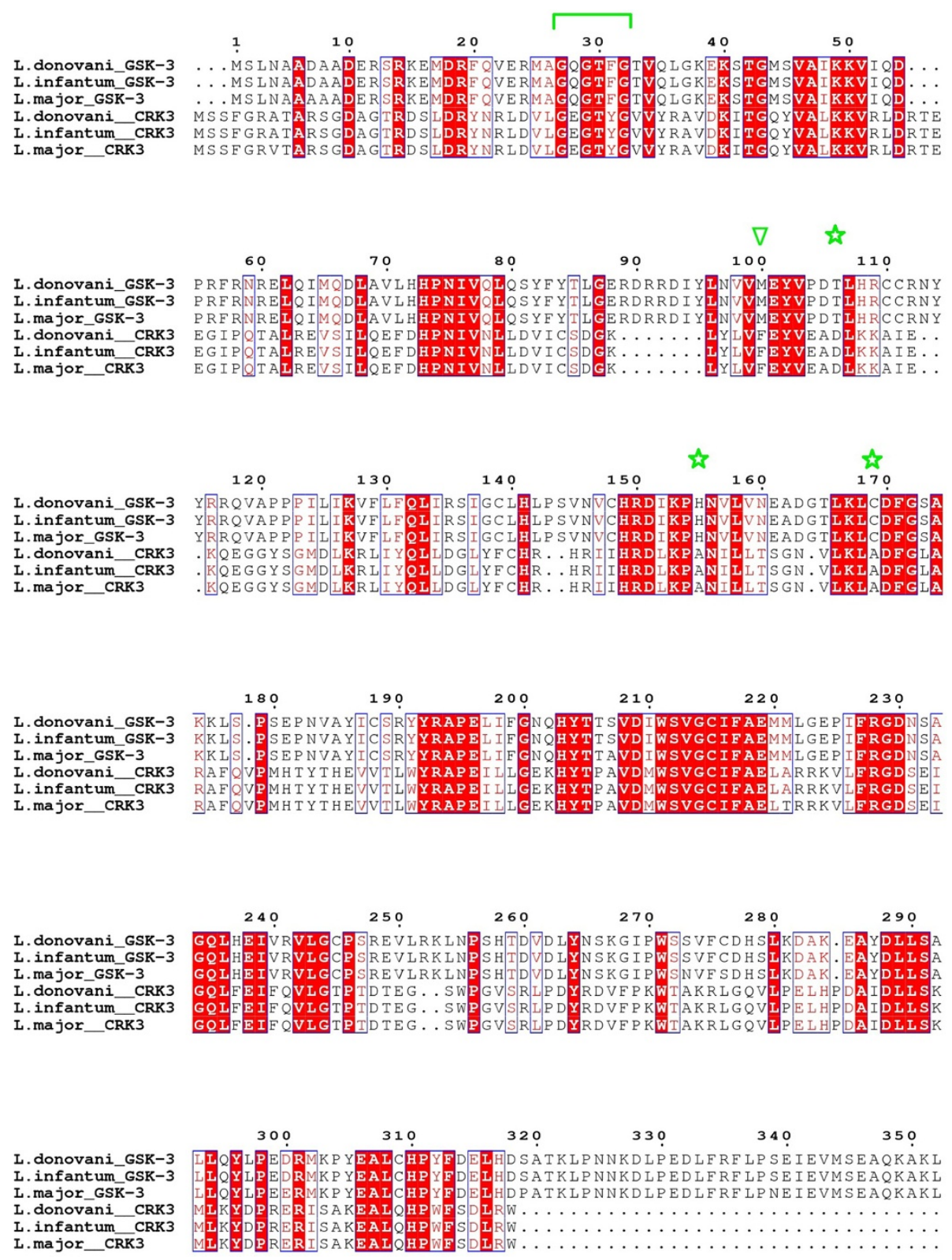

Figure 3 Multiple sequence alignment of GSK-3 and CRK3 from three related Leishmania species. The multiple sequence alignment depicts the high homology between GSK-3 and CRK3 of three Leishmania species, namely L. donovani, L. infantum and L. major (Uniprot codes: A6N857, A4HXQ3, Q4QE15 for GSK-3 and Q4K8Z1, A4ICT0, Q96526 for CRK3, respectively). The gatekeeper positions as well as the three non-conserved residues of the ribose sub-site are highlighted by green stars and the glycine-rich loop is marked by a green bracket. Alignment was performed using ClustalW with default settings and the depiction was prepared using ESPript software (http://espript.ibcp.fr) [37,38]. 
compound for the association of LGSK-3 inhibition and the accumulation in subG0/G1 phase [13]. In addition, the contribution of $\mathbf{1 1}$ and $\mathbf{1 7}$ to the mode and timing of cell-death was tested. Thus, apoptotic-like cell-death was assessed by measuring membrane fluidity perturbation and membrane impermeability, until the late stages of the process. Double staining assay with AnnexinVFITC and PI was used, which allows the differentiation between early apoptotic (AnnexinV-FITC positive), late apoptotic (AnnexinV-FITC and PI positive), necrotic (PI positive) and viable cells (unstained) [32-36]. Incubation of cells with $0.02 \%(\mathrm{v} / \mathrm{v})$ DMSO showed negative staining for both AnnexinV and PI, as 93\% of the cells were viable at all time-points (Figure 2). Compounds $\mathbf{1 1}$ and $\mathbf{1 7}$ caused a rapid increase of late apoptotic or necrotic cells after $48 \mathrm{hrs}$ of incubation in the parasites (late apoptotic cells: $42 \%$ and $28 \%$ respectively, necrotic cells: $5.42 \%$ and $4.28 \%$ respectively). These results are in agreement with the mode of cell death caused by $5-\mathrm{Me}-6-\mathrm{BIO}$ and LGSK-3 inhibition as $48 \mathrm{hrs}$ treatment with the compound resulted in an increase of the late apoptotic population [13]. On the other hand, parasites incubated with the LCRK3 inhibitor 6BIO, displayed an equal increase on early and late apoptotic cells [13], different to the cell-death pattern induced by compounds $\mathbf{1 1}$ and $\mathbf{1 7}$ displayed. In general, the above observations strengthen our results and suggest that the selectivity of the compounds $\mathbf{1 1}$ and $\mathbf{1 7}$ towards LGSK-3 is also mirrored in the parasite.

To better explain this shift towards LGSK-3, we performed a comparative structural analysis of LGSK-3 and

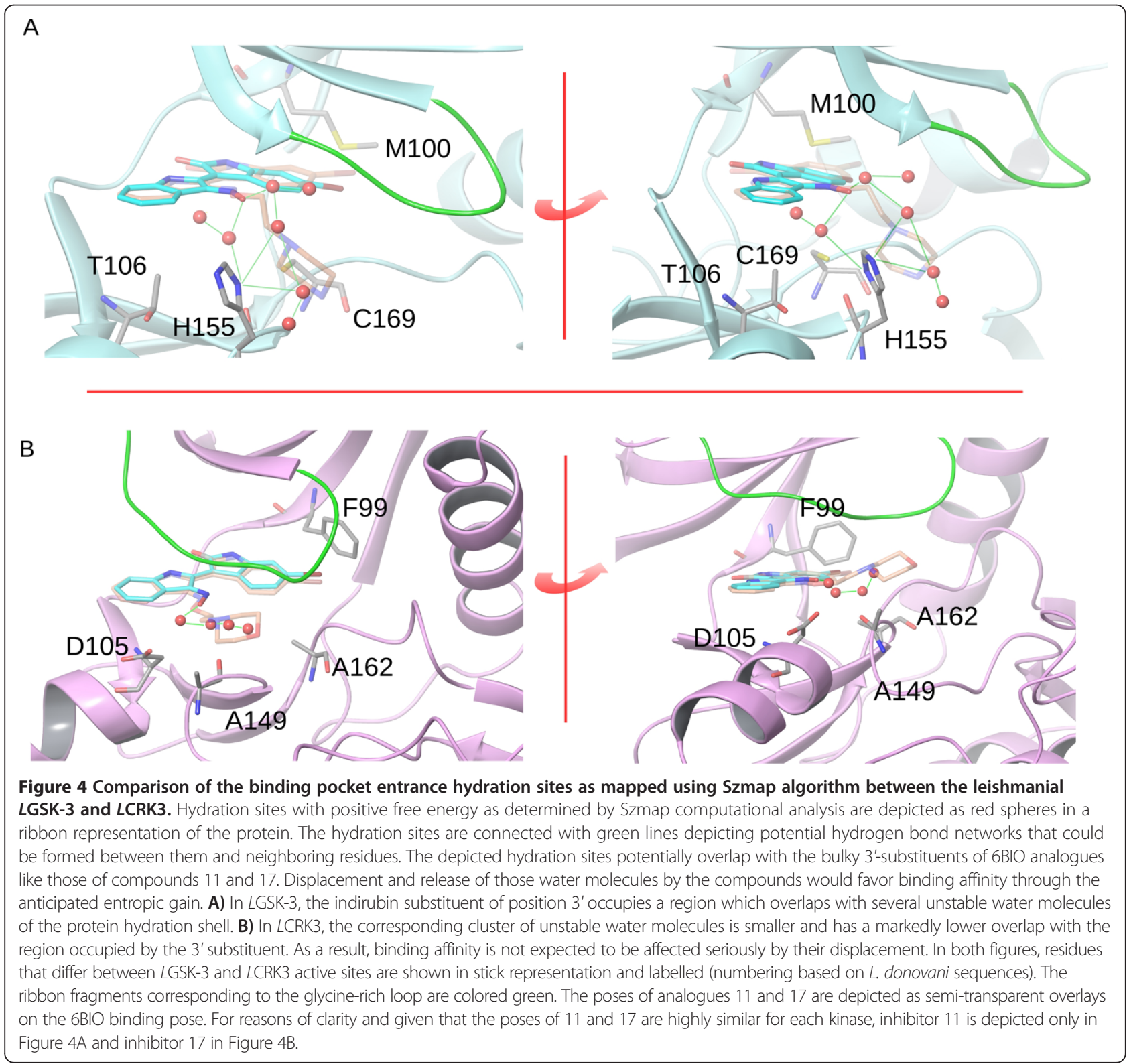


LCRK3 homologue pairs (Figure 3) of three Leishmania species (L. major, L. donovani, L. infantum) [37,38]. Initial results showed that the active site residues demonstrated a high degree of sequence conservation within the group of studied homologues, with the most important differences being the replacement of the gatekeeper M100 ${ }^{L G S K-3}$ to F99 ${ }^{L C R K 3}$. However, several variations were located at the vicinity of the binding pocket of the three LGSK-3/LCRK3 pairs and primarily on the glycinerich loop and at the ribose and phosphate binding subsites of the kinases. In LGSK-3 the Gly-loop motifs is ${ }^{27} \mathrm{GQGTFG}^{32}$ while in LCRK3 it is ${ }^{30} \mathrm{GEGTYG}^{35}$. At the ribose site, $\mathrm{T} 106^{L \mathrm{GSK}-3}$ is replaced by $\mathrm{D} 105^{L \mathrm{LCRK} 3}$, while at the phosphate site $\mathrm{H} 155^{L \mathrm{GSK}-3}$ is replaced by $\mathrm{A} 149^{L \mathrm{CRK} 3}$ and $C 169^{L G S K-3}$ by $A 162^{L C R K 3}$. Those variations were identified as of possible importance with respect to the determination of the binding pocket hydration pattern. Moreover, it was suggested that differences in hydration could be indirectly induced through the sequence variations located at the glycine-loop by affecting its flexibility, which in turn might influence the interaction of the loop with the water molecules solvating the ribose and phosphate sub-sites.

To assess that effect, the computational mapping of the hydration sites over the surface of the studied kinases was performed using Szmap algorithm [39,40]. Analysis of the hydration showed a pronounced difference on the predicted thermodynamic properties of water molecules, which would be expected to form the first hydration shell close to the ribose and phosphate binding sub-sites of each protein. More specifically, a cluster of waters of positive free energy is present at the aforementioned locations in the LGSK3 structures but not in the LCRK3 homologues (Figure 4). This cluster defines an area at which substitution of the solvent by polar ligand groups would favor binding affinity while replacement by hydrophobic groups would instead affect affinity in an unfavorable manner. Given the well-known impact of protein desolvation on binding affinity, it was hypothesized that compounds that bind the kinases through specific interactions accommodated at that specific part of the cavity could have a different affinity among the otherwise highly similar active sites of LGSK-3 and LCRK3.

Consistent with this hypothesis is the fact that the 6bromo-3' -nitrogen-substituted analogues identified as lead molecules in the $L$. donovani growth inhibition assay, shifted their selectivity towards LGSK-3 over LCRK3 (11-17, Table 1). Those analogues could selectively target LGSK-3 by binding adjacent to the aforementioned region of the pocket, overlapping with the hydration sites of interest and thus gaining affinity due to the entropic effect of displacing relatively unstable water molecules from the kinase first hydration shell.

\section{Conclusions}

In conclusion, the present study describes the screening of a small and diverse indirubin library for compounds with activity inhibiting the growth of leishmanial parasites and the identification of a class of 3 '-bulky amino substituted indirubin analogues displaying inhibition and specificity on LGSK-3. Among these, derivatives $\mathbf{1 1}$ and $\mathbf{1 7}$ exerted a very good antileishmanial activity $\left(\mathrm{GI}_{50}<0.76 \mu \mathrm{M}\right.$ in $L$. donovani promastigotes and $\mathrm{GI}_{50}<1.22 \mu \mathrm{M}$ in $L$. donovani intracellular amastigotes), and a good selectivity index (>8). Compound 11 possessed the highest LGSK-3 over LCRK3 selectivity index (>33-fold). Thus, these compounds are considered as an initial scaffold for the design of LGSK-3 selective inhibitors and therefore for the design of potent antileishmanial agents.

\section{Competing interests}

The authors declare that they have no conflict of interest.

\section{Authors' contributions}

$\mathrm{KS}, \mathrm{A}-\mathrm{LS}$ and DS conceived and designed the study. AE, NG-K, KV, MK and DS carried out the experiments and analyzed the data. VM and EM carried out the computational analysis and analyzed the data. AE, A-LS, KS, DS, NG, VM and KV drafted and revised the manuscript. AA, EM provided analysis tools and/or contributed to the critical revision of the manuscript. All authors read and approved the final version of the manuscript.

\section{Acknowledgements}

The authors wish to thank the FP7-PEOPLE-2010-IRSES program "ChemBioFight" (Exploring chemical biodiversity with innovative approaches for fighting Chagas and leishmaniasis, grant number 269031) for financial support. The authors would like to acknowledge the COST Action BM0802 for the useful talks and advice on parasitic cell-death mechanisms and for funding the Institute of European Culture And Education. The authors are thankful to Dr. K. Grant for providing the LCRK3 transgenic L. mexicana parasites.

\section{Author details}

'Laboratory of Molecular Parasitology, Department of Microbiology, Hellenic Pasteur Institute, 127 Vas.Sofias Ave, 11521 Athens, Greece. 'Laboratories of Pharmacognosy and Pharmaceutical Chemistry, Department of Pharmacy, University of Athens, Panepistimiopolis-Zografou, 15771 Athens, Greece. ${ }^{3}$ Department of Pharmacognosy and Natural Product Chemistry, Faculty of Pharmacy, National and Kapodistrian University of Athens, Athens, Greece.

Received: 9 December 2013 Accepted: 3 May 2014

Published: 20 May 2014

\section{References}

1. WHO: Control of Leishmaniases, WHO Technical Report Series. ; 2010:949.

2. Luder CG, Campos-Salinas J, Gonzalez-Rey E, van Zandbergen G: Impact of protozoan cell death on parasite-host interactions and pathogenesis. Parasit Vector 2010, 3:116.

3. Dostalova A, Volf P: Leishmania development in sand flies: parasite-vector interactions overview. Parasit Vector 2012, 5:276.

4. Stuart K, Brun R, Croft S, Fairlamb A, Gurtler RE, McKerrow J, Reed S, Tarleton R: Kinetoplastids: related protozoan pathogens, different diseases. J Clin Invest 2008, 118(4):1301-1310.

5. Croft SL, Sundar S, Fairlamb AH: Drug resistance in leishmaniasis. Clin Microbio/ Rev 2006, 19(1):111-126.

6. Polonio T, Efferth T: Leishmaniasis: drug resistance and natural products (review). Int J Mol Med 2008, 22(3):277-286.

7. Skropeta D, Pastro N, Zivanovic A: Kinase inhibitors from marine sponges. Mar Drugs 2011, 9(10):2131-2154.

8. Walker SR, Carter EJ, Huff BC, Morris JC: Variolins and related alkaloids. Chem Rev 2009, 109(7):3080-3098.

9. Meijer L, Raymond E: Roscovitine and other purines as Kinase inhibitors. From starfish oocytes to clinical trials. Acc Chem Res 2003, 36(6):417-425. 
10. Tahtouh T, Elkins JM, Filippakopoulos P, Soundararajan M, Burgy G, Durieu E, Cochet C, Schmid RS, Lo DC, Delhommel F, Oberholzer AE, Pearl LH, Carreaux F, Bazureau JP, Knapp S, Meijer L: Selectivity, cocrystal structures, and neuroprotective properties of leucettines, a family of protein kinase inhibitors derived from the marine sponge alkaloid leucettamine $b$. J Med Chem 2012, 55(21):9312-9330.

11. Meijer $L$, Skaltsounis AL, Magiatis P, Polychronopoulos P, Knockaert M, Leost M, Ryan XP, Vonica CA, Brivanlou A, Dajani R, Crovace C, Tarricone C, Musacchio A, Roe SM, Pearl L, Greengard P: GSK-3-selective inhibitors derived from Tyrian purple indirubins. Chem Biol 2003, 10(12):1255-1266.

12. Liu J, Hu Y, Waller DL, Wang J, Liu Q: Natural products as kinase inhibitors. Nat Prod Rep 2012, 29(3):392-403.

13. Xingi E, Smirlis D, Myrianthopoulos V, Magiatis P, Grant KM, Meijer L, Mikros E, Skaltsounis AL, Soteriadou K: 6-Br-5methylindirubin-3'oxime (5-Me-6-BIO) targeting the leishmanial glycogen synthase kinase-3 (GSK-3) short form affects cell-cycle progression and induces apoptosis-like death: exploitation of GSK-3 for treating leishmaniasis. Int J Parasito/ 2009, 39(12):1289-1303.

14. Hoessel R, Leclerc S, Endicott JA, Nobel MEM, Lawrie A, Tunnah P, Leost M, Damiens E, Marie D, Marko D, Niederberger E, Tang W, Eisenbrand G, Meijer L: Indirubin, the active constituent of a Chinese antileukaemia medicine, inhibits cyclin-dependent kinases. Nat Cell Biol 1999, 1(1):60-67.

15. Vougogiannopoulou K, Skaltsounis AL: From Tyrian purple to kinase modulators: naturally halogenated indirubins and synthetic analogues. Planta Med 2012, 78(14):1515-1528.

16. Polychronopoulos $P$, Magiatis $P$, Skaltsounis AL, Myrianthopoulos V, Mikros E, Tarricone A, Musacchio A, Roe SM, Pearl L, Leost M, Greengard P, Meijer L: Structural basis for the synthesis of indirubins as potent and selective inhibitors of glycogen synthase kinase- 3 and cyclin-dependent kinases. J Med Chem 2004, 47(4):935-946.

17. Naula C, Parsons M, Mottram JC: Protein kinases as drug targets in trypanosomes and Leishmania. Biochim Biophys Acta 2005, 1754(1-2):151-159.

18. Grant KM, Dunion MH, Yardley V, Skaltsounis AL, Marko D, Eisenbrand G, Croft SL, Meijer L, Mottram JC: Inhibitors of Leishmania mexicana CRK3 cyclin-dependent kinase: chemical library screen and antileishmanial activity. Antimicrob Agents Chemother 2004, 48(8):3033-3042.

19. Ojo KK, Gillespie JR, Riechers AJ, Napuli AJ, Verlinde CL, Buckner FS, Gelb MH, Domostoj MM, Wells SJ, Scheer A, Wells TN, Van Voorhis WC: Glycogen synthase kinase 3 is a potential drug target for African trypanosomiasis therapy. Antimicrob Agents Chemother 2008, 52(10):3710-3717.

20. Walker RG, Thomson G, Malone K, Nowicki MW, Brown E, Blake DG, Turner NJ, Walkinshaw MD, Grant KM, Mottram JC: High throughput screens yield small molecule inhibitors of Leishmania CRK3:CYC6 cyclin-dependent kinase. PLoS Negl Trop Dis 2011, 5(4):e1033.

21. Hassan P, Fergusson D, Grant KM, Mottram JC: The CRK3 protein kinase is essential for cell cycle progression of Leishmania mexicana. Mol Biochem Parasitol 2001, 113(2):189-198.

22. Cleghorn LA, Woodland A, Collie IT, Torrie LS, Norcross N, Luksch T, Mpamhanga C, Walker RG, Mottram JC, Brenk R, Frearson JA, Gilbert IH, Wyatt PG: Identification of inhibitors of the Leishmania cdc2-related protein kinase CRK3. ChemMedChem 2011, 6(12):2214-2224.

23. Vougogiannopoulou K, Ferandin Y, Bettayeb K, Myrianthopoulos V, Lozach O, Fan Y, Johnson CH, Magiatis P, Skaltsounis AL, Mikros E, Meijer L: Soluble 3',6substituted indirubins with enhanced selectivity toward glycogen synthase kinase -3 alter circadian period. J Med Chem 2008, 51(20):6421-6431.

24. Ferandin $Y$, Bettayeb K, Kritsanida M, Lozach O, Polychronopoulos P, Magiatis $P$, Skaltsounis AL, Meijer L: 3'-Substituted 7-halogenoindirubins, a new class of cell death inducing agents. J Med Chem 2006, 49(15):4638-4649.

25. Mikus J, Steverding D: A simple colorimetric method to screen drug cytotoxicity against Leishmania using the dye Alamar Blue. Parasitol Int 2000, 48(3):265-269.

26. Tsagozis P, Karagouni E, Dotsika E: Function of CD8+ T lymphocytes in a self-curing mouse model of visceral leishmaniasis. Parasitol Int 2005, 54(2):139-146

27. Papageorgiou FT, Soteriadou KP: Expression of a novel Leishmania gene encoding a histone $\mathrm{H} 1$-like protein in Leishmania major modulates parasite infectivity in vitro. Infect Immun 2002, 70(12):6976-6986.

28. Georgopoulou K, Smirlis D, Bisti S, Xingi E, Skaltsounis L, Soteriadou K: In vitro activity of 10-deacetylbaccatin III against Leishmania donovani promastigotes and intracellular amastigotes. Planta Med 2007, 73(10):1081-1088.
29. Droucheau E, Primot A, Thomas V, Mattei D, Knockaert M, Richardson C, Sallicandro P, Alano P, Jafarshad A, Baratte B, Kunick C, Parzy D, Pearl L, Doerig C, Meijer L: Plasmodium falciparum glycogen synthase kinase-3: molecular model, expression, intracellular localisation and selective inhibitors. Biochim Biophys Acta 2004, 1697(1-2):181-196

30. Prime, Version 3.1. New York: Schrodinger LLC; 2012.

31. Fytas C, Zoidis G, Tzoutzas N, Taylor MC, Fytas G, Kelly JM: Novel lipophilic acetohydroxamic acid derivatives based on conformationally constrained spiro carbocyclic 2,6-diketopiperazine scaffolds with potent trypanocidal activity. J Med Chem 2011, 54(14):5250-5254.

32. Smirlis D, Boleti $H$, Gaitanou M, Soto M, Soteriadou K: Leishmania donovani Ran-GTPase interacts at the nuclear rim with linker histone H1. Biochem J 2009, 424(3):367-374.

33. Smirlis D, Duszenko M, Ruiz AJ, Scoulica E, Bastien P, Fasel N, Soteriadou K: Targeting essential pathways in trypanosomatids gives insights into protozoan mechanisms of cell death. Parasit Vector 2010, 3:107.

34. Jimenez-Ruiz A, Alzate JF, Macleod ET, Luder CG, Fasel N, Hurd H: Apoptotic markers in protozoan parasites. Parasit Vector 2010, 3:104.

35. Kaczanowski S, Sajid M, Reece SE: Evolution of apoptosis-like programmed cell death in unicellular protozoan parasites. Parasit Vector 2011, 4:44

36. Taylor-Brown $\mathrm{E}$, Hurd $\mathrm{H}$ : The first suicides: a legacy inherited by parasitic protozoans from prokaryote ancestors. Parasit Vector 2013, 6(1):108.

37. McWilliam H, Li W, Uludag M, Squizzato S, Park YM, Buso N, Cowley AP, Lopez R: Analysis Tool Web Services from the EMBL-EBI. Nucleic Acids Res 2013, 41:W597-W600. Web Server issue.

38. Gouet $\mathrm{P}$, Robert $\mathrm{X}$, Courcelle E: ESPript/ENDscript: Extracting and rendering sequence and $3 D$ information from atomic structures of proteins. Nucleic Acids Res 2003, 31(13):3320-3323.

39. SZMAP 1.2.0.7: OpenEye Scientific Software, Santa Fe, NM. 2013. http://www. eyesopen.com

40. Grant JA, Pickup BT, Nicholls A: A smooth permittivity function for PoissonBoltzmann solvation methods. J Comput Chem 2001, 22(6):608-640.

doi:10.1186/1756-3305-7-234

Cite this article as: Efstathiou et al:: An inhibitor-driven study for enhancing the selectivity of indirubin derivatives towards leishmanial Glycogen Synthase Kinase-3 over leishmanial cdc2-related protein kinase 3. Parasites \& Vectors 2014 7:234

\section{Submit your next manuscript to BioMed Central and take full advantage of:}

- Convenient online submission

- Thorough peer review

- No space constraints or color figure charges

- Immediate publication on acceptance

- Inclusion in PubMed, CAS, Scopus and Google Scholar

- Research which is freely available for redistribution 